\title{
Ion micro-beam analyses of dust particles and co-deposits from JET with the ITER-like wall
}

\author{
Stjepko Fazinić* ${ }^{1}$, Tonči Tadić ${ }^{1}$, Marin Vukšić ${ }^{1}$, Marek Rubel ${ }^{2}$, Per Petersson², Elżbieta Fortuna- \\ Zaleśna $^{3}$, Anna Widdowson ${ }^{4}$ \\ ${ }^{1}$ Ruđer Bošković Institute, Bijenička 54, 10000 Zagreb, Croatia. \\ ${ }^{2}$ Royal Institute of Technology (KTH), Department of Fusion Plasma Physics, School of Electrical Engineering, \\ Teknikringen 31, 10044 Stockholm, Sweden. \\ ${ }^{3}$ Warsaw University of Technology, Faculty of Materials Science and Technology, Woloska 141, 02-507 Warsaw, Poland. \\ ${ }^{4}$ Culham Centre for Fusion Energy, Culham Science Centre, Abingdon, OX14 3DB, UK.
}

\begin{abstract}
Generation of metal dust in the JET tokamak with the ITER-like wall (ILW) is a topic of vital interest to next-step fusion devices because of safety issues with plasma operation. Simultaneous Nuclear Reaction Analysis (NRA) and ParticleInduced X-ray Emission (PIXE) with a focused $4 \mathrm{MeV}^{3} \mathrm{He}$ micro-beam was used to determine the composition of dust particles related to the JET operation with the ILW. The focus was on 'Be-rich particles' collected from the deposition zone on the inner divertor tile. The particles found are composed of a mix of co-deposited species up to $120 \mu \mathrm{m}$ in size with a thickness of 30-40 $\mu \mathrm{m}$. The main constituents are D from the fusion fuel, Be and $\mathrm{W}$ from the main plasma-facing components, and $\mathrm{Ni}$ and $\mathrm{Cr}$ from the Inconel grills of the antennas for auxiliary plasma heating. Elemental concentrations were estimated by iterative NRA-PIXE analysis. Two types of dust particles were found: (i) larger Be-rich particles with Be concentrations above 90 at $\%$ with a deuterium presence of up to 3.4 at $\%$ and containing $\mathrm{Ni}, \mathrm{Cr}, \mathrm{W}, \mathrm{Fe}, \mathrm{Cu}$ and $\mathrm{Ti}$ in lower concentrations and (ii) small particles rich in $\mathrm{Al}$ and/or $\mathrm{Si}$ that were in some cases accompanied with other elements, such as $\mathrm{Fe}, \mathrm{Cu}$ or $\mathrm{Ti}$; or $\mathrm{W}$ and Mo.
\end{abstract}

Plasma-surface interaction processes in devices for controlled thermonuclear fusion cause erosion of plasma-facing components (PFCs). This is followed by migration and re-deposition of eroded species and, thus, the modification of wall materials and fusion plasma. The plasma dynamics in a tokamak include transport of eroded particles down toward the divertor. Joint European Torus (JET) is the world's largest operating tokamak that uses identical materials (Be and W) as the International Thermonuclear Experimental Reactor (ITER), which is under construction in France. JET has unique capabilities to handle Be and radioactive tritium (T). The wall materials include $\mathrm{Be}$ in the main chamber wall and $\mathrm{W}$ in the divertor ${ }^{1,2}$. The same material configuration will be implemented at the ITER ${ }^{3,4}$; therefore, JET with its ITER-like wall (JET-ILW) serves as a large-scale test bed for plasma operation with metal walls.

Some parts of material eroded from the walls will be converted into dust. Its formation in present-day machines does not pose operational issues because the quantities are small, especially with the presence of metal walls. In JET, it is around $1 \mathrm{~g}$ per experimental campaign that comprises $19-25 \mathrm{~h}^{5,6}$. However, in ITER, the generation of large quantities of loose particles will create serious problems because dust is a radiological ( $\mathrm{T}$ and activation products) and toxic (e.g., Be) hazard. The typical dust particle size is likely to be $<150 \mu \mathrm{m}$. It is chemically reactive with water and oxygen in the case of a water leak or of a massive air ingress.

For that reason, comprehensive characterization of the wall components ${ }^{7-9}$ and dust has been conducted in current fusion devices. A list of dust studies published until year 2011 mostly for carbon wall machines has been compiled by B. Braams ${ }^{3}$, whereas recent studies have involved JET-ILW ${ }^{6,10,11}$ and ASDEX Upgrade ${ }^{12}$. The first dust study for JET-ILW was reported in 2015 by BaronWiechec et al. ${ }^{10}$. The analysis was performed on samples collected after venting JET-ILW during its first shutdown. Sampling from the upper divertor region, which is the most critical area from a deposition point of view, showed the presence of two types of Be particles: flakes of co-deposits and small droplets. Both of these particle types are of considerable importance for ITER ${ }^{10}$. The composition and internal structure of the dust collected on carbon stickers from various regions of the divertor were studied after the second JET experimental campaign with the ILW (2013-14) and were reported by Fortuna-Zaleśna et al. ${ }^{6,11}$. Two major particle classes of importance to ITER were identified: (i) mixed deposits rich in Be and (ii) metal droplets (Be, W, and Ni) born in melting events of the wall materials.

In these studies, the composition, size, and topography of the dust particles were analyzed by SEM/TEM, FIB, electron diffraction, and WDX/EDX. Regarding the composition, the reports provide only qualitative information (only elemental identification). The major elements determined by SEM were identified and supported by 2D elemental maps and by selected EDX spectra in the low X-ray energy region up to $2 \mathrm{keV}$. In addition to $\mathrm{Be}$, the presence of other elements, including $\mathrm{W}, \mathrm{Ni}, \mathrm{Mo}, \mathrm{Al}, \mathrm{C}, \mathrm{O}, \mathrm{F}, \mathrm{S}, \mathrm{Cl}$, and $\mathrm{S}$, was reported. Moreover, the distribution and content of deuterium (D) in the respective dust grains was not studied for technical reasons since EDX cannot detect it. It is also well known that light elements, such as Be, are difficult to trace with EDX since 
they are much more likely to emit Auger electrons instead of the characteristic X-rays. The Be fluorescence yield is very low, and its reported values in the literature are between 0.0003 and $0.00036^{13-15}$ with reported uncertainties of 20-30\%. In addition, its $\mathrm{K} \alpha$ $\mathrm{X}$-ray energy is only $108 \mathrm{eV}$ and is easily attenuated in the presence of $\mathrm{C}$ and/or O. In principle, SEM EDX can provide only surface information at depths up to $1 \mu \mathrm{m}$, and in the case of Be, even less. For these reasons, it is almost impossible to perform a quantitative analysis of the related particles with EDX. However, it is important to know the concentrations of the major constituents of loose particles, especially of toxic elements like Be, D from fuel and heavy metals.

The main goal of this work was to simultaneously record quantitative data of composition of the dust particles related to the JET operation with the ILW, focusing on 'Be-rich particles' from the upper divertor region. The main interest was on the main constituents, including $\mathrm{D}, \mathrm{Be},(\mathrm{C}), \mathrm{Ni}$, and $\mathrm{W}$, and of particular interest and importance was the determination of the concentration ratios of $\mathrm{Be}$ and D. Only Ion Beam Analysis (IBA) methods ${ }^{16-19}$ combined with ion beams focused to $\mu \mathrm{m}$ dimensions can provide answers for this type of material. IBA methods are capable of detecting all the above elements, including D.

In addition, compared to SEM, IBA methods can provide information on the presence of light elements at much deeper depths $(\approx$ $15 \mu \mathrm{m}$ or more). Among the IBA methods, RBS (Rutherford Backscattering Spectroscopy) is frequently used for precise and accurate depth profiling of thin films ${ }^{20}$, while Nuclear Reaction Analysis (NRA) and/or Particle Induced Gamma Ray Emission (PIGE) can be used to quantify concentrations of light elements, such as D, Be, C, O, Mg, and Na. Simultaneously, Particle Induced X-Ray Emission (PIXE) can be used to quantify Na and heavier elements ${ }^{21-25}$. Microprobe IBA methods have also been used in the past for studies of PFC surfaces ${ }^{26-35}$. For the present study, we decided to work with ${ }^{3} \mathrm{He}$ ion beams since the nuclear reaction $\mathrm{D}\left({ }^{3} \mathrm{He}\right.$, $\left.{ }^{4} \mathrm{He}\right) \mathrm{p}$ is widely used to detect $\mathrm{D}^{36}$. Additionally, it can be used for the detection of $\mathrm{Be}, \mathrm{C}^{37}$ and other light elements, such as $\mathrm{N}$ and $\mathrm{B}$. To our knowledge, this is the first work in which these techniques has been applied for the characterization of locally sampled dust from fusion devices.

\section{EXPERIMENTAL SECTION}

Dust was sampled using a sticky carbon pad from the inner divertor tile after the second ILW campaign (2013-2014), which involved $19.5 \mathrm{~h}$ of plasma operation (13.5 h of X-point plasma) with a total energy input of $201 \mathrm{GJ}$. The drawing in Fig. 1(a) shows the poloidal divertor cross section with the dust sampling positions marked. In the insert, there is a plastic cup, and in the bottom, there is a tab equipped with a sticky pad. This procedure delivers samples that are ready for further analyses by ion or electron beams. All steps of sample preparation, shipment and handling complied with established procedures ${ }^{38}$. Sampling on the adhesive carbon pad made the dust particles immobile, thus eliminating the risk for environmental contamination. The image in Fig. 1(b) shows the High Field Gap Closure tile (HFGC, Tile 0) from the inner divertor. The tile has two distinct areas: a part without deposition on the shiny tungsten coating and a zone covered by co-deposit that contains a mixture of elements. Sampling, which is marked with a red spot, was performed in this deposition zone. In the insert, there is an actual sample with a marked area of micro-analysis. There is only a small amount of matter sticking to the pad (especially the shiny region on the left), thus indicating that dust and/or co-deposit was sticking well to the tile surface.

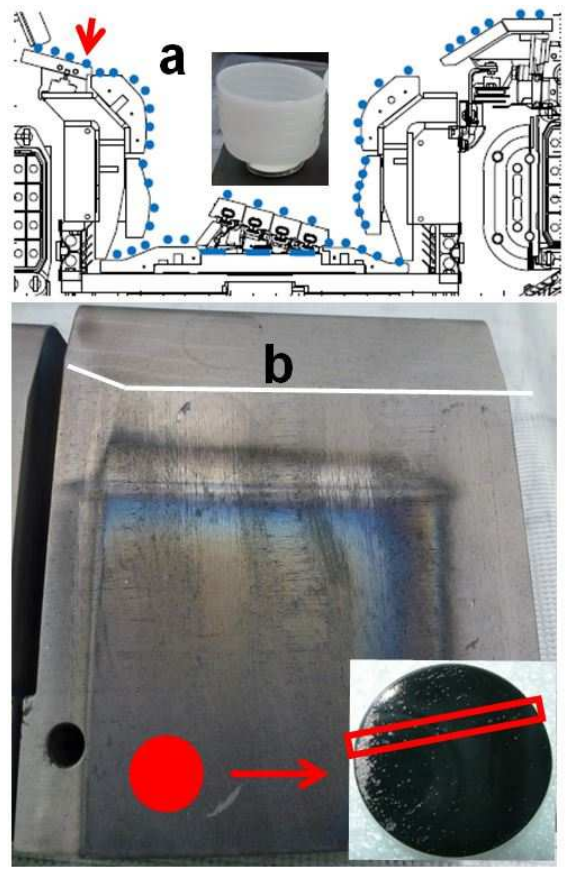

Figure 1. (a) Poloidal cross-section of the JET-ILW divertor with the dust sampling position marked; (b) inner divertor tile and the position of dust sampling for these studies. The insert shows the carbon sticky pad used for dust sampling.

Dust morphology studies were performed at the Warsaw University of Technology, Poland. For this purpose, scanning electron microscopy (SEM, Hitachi SU-8000 FE-SEM) combined with energy-dispersive X-ray spectroscopy using a silicon drift detector (EDS, Thermo Scientific Ultra Dry) capable of detecting both Be and heavier elements was used. The electron beam energy was typically $10 \mathrm{keV}$; however, on several occasions, low energy (1 or $2 \mathrm{keV}$ ) was applied. 
IBA measurements were performed at the Ruđer Bošković Institute using the ion microprobe facility ${ }^{39}$. However, the standard ion microprobe chamber configuration was modified to allow simultaneous PIXE and NRA measurements with an installed nonstandard large area and large depth particle detector. The ${ }^{3} \mathrm{He}$ ion beam from the Alphatross ion source was accelerated to $4 \mathrm{MeV}$ by the $6 \mathrm{MV}$ tandem electrostatic accelerator and focused by a triplet magnetic quadrupole lens system to an approximate $6 \mu \mathrm{m}$ spot size and was raster scanned over selected samples. Accurate measurements of ion beam currents and the collected charge from thick targets in microprobe systems is difficult and often an impossible task. To test the ion beam current variations with time, we periodically measured the Be NRA yield from the Be foil, and the overall variation was found to be about $10 \%$ from the average value. $\mathrm{Ni}$ and $\mathrm{Cu}$ grids (mesh 500 and 1000) were used to estimate the ion microbeam resolution and the size of the raster scan areas from the $2 \mathrm{D}$ distribution of the $\mathrm{Ni} \mathrm{K}$ and $\mathrm{Cu} \mathrm{L}$ PIXE X-ray line intensities. The focused ${ }^{3} \mathrm{He}$ ion beam was scanned over a rectangular scan pattern with a size of $320 \times 320 \mu \mathrm{m}^{2}$ and 128 x 128 pixels. Simultaneously, NRA and PIXE spectra were collected.

PIXE spectra were collected using our standard $30 \mathrm{~mm}^{2} \mathrm{Si}(\mathrm{Li})$ detector with a $12.5 \mu \mathrm{m} \mathrm{Be}$ window placed at $135^{\circ}$ relative to the beam direction at a distance of about $4 \mathrm{~cm}$ from the target with the detector solid angle of $0.0176 \mathrm{sr}$. This detector is regularly used at our microprobe and is calibrated ${ }^{40}$ using a set of thin film calibration standards obtained from the Micromatter Company. The effective detector X-ray energy resolution was about $160 \mathrm{eV}$ (for the $\mathrm{Mn} \mathrm{K \alpha}$ line).

The NRA spectra were detected by the ORTEC BA-022-300-2000 Partially Depleted Silicon Surface Barrier detector (PDSSB) with a depletion depth of $2000 \mu \mathrm{m}$ and a nominal active area of $300 \mathrm{~mm}^{2}$ collimated to $230 \mathrm{~mm}^{2}$ and placed at $135 \mathrm{deg}$. Due to its large area, the detector covered scattering angles of $\pm 19 \mathrm{deg}$ from the central $135 \mathrm{deg}$. The detector was positioned as close as possible to the sample (at a distance of approximately $2.2 \mathrm{~cm}$ ) to increase the solid angle for particle detection. The ratio of the NRA and PIXE detector solid angles $\left(\Omega_{\mathrm{NRA}} / \Omega_{\mathrm{PIXE}}\right)$ was determined without the need to measure the ion beam charge by simultaneously measuring the PIXE and RBS spectra of pure Ti and Ni thick foils obtained from Goodfellow and a thin Micromatter standard Cr film $\left(48.5 \mu \mathrm{m} / \mathrm{cm}^{2}\right)$ on polyester backing using a focused $4 \mathrm{MeV}^{3} \mathrm{He}$ ion beam in the same detector-sample geometry as used for the actual measurements on the dust samples. The resulting $\Omega_{\mathrm{NRA}} / \Omega_{\mathrm{PIXE}}$ ratio was determined to be $26.3 \pm 1.4$, from which the NRA detector solid angle was deduced to be $0.462 \mathrm{sr}$ with a $6 \%$ uncertainty. For the NRA measurements, in front of the PDSSB detector, two foils were placed to absorb the low-energy elastically backscattered primary particles from the target and to reduce pile-up background. These included a Goodfellow Ti foil with a nominal thickness of $9 \mu \mathrm{m}$ and a Lebow Company Mylar foil of a $13 \mu \mathrm{m}$ nominal thickness. We measured the actual thickness of both foils by Elastic Backscattering Spectroscopy (EBS). The Ti foil thickness of $10.5 \mu \mathrm{m}$ was determined with $2 \mathrm{MeV}$ protons ${ }^{41}$, and the Mylar foil thickness of $11.9 \mu \mathrm{m}$ was determined with $1.6 \mathrm{MeV}$ protons (with estimated uncertainties below $2 \%$. The entire setup was kept in vacuum $\left(10^{-7} \mathrm{bar}\right)$ ).

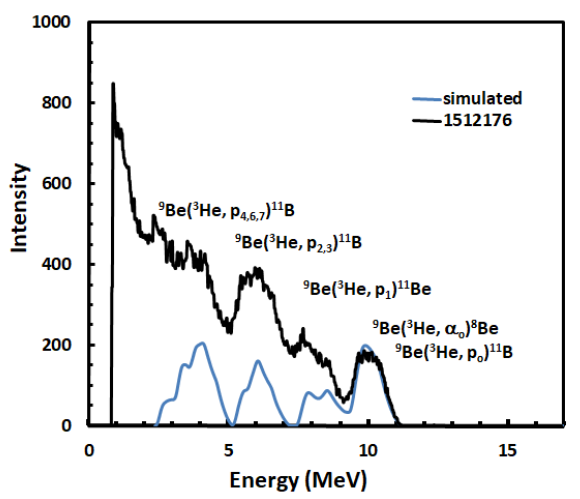

Figure 2. Measured NRA spectrum of the thick Be foil used as the standard and simulated NRA spectrum. Contributions from the ${ }^{9} \mathrm{Be}\left({ }^{3} \mathrm{He}\right.$, $\left.\mathrm{p}_{\mathrm{i}}\right)^{11} \mathrm{~B}$ reactions available at IBANDL are seen. The misfit at lower energies is due to neglecting the multiple channels that are open that cannot presently be simulated.

PIXE and NRA data were digitally recorded in list files. The data acquisition (DAQ) system used at the microprobe is composed of two parts: an in-house developed software package called SPECTOR and hardware based on Xilinx Virtex 6 FPGAs. SPECTOR is designed to be a general purpose program that is able to interface with a wide variety of hardware while providing a consistent user interface. The initial version of SPECTOR was described in Bogovac et al. ${ }^{42}$ but has since evolved with new functionalities and features. The DAQ hardware based on Xilinx FPGAs allows for interfacing up to 8 NIM crate ADC modules. It more importantly modernizes the DAQ process by taking advantage of the power of FPGAs to provide 8 additional channels of digital pulse processing for pulse height analysis. Furthermore, using the flexibility of the FPGAs, the same system has been reconfigured to allow time-based MeV-SIMS experiments and is coupled with motorized stages to perform RBS channeling measurements.

Table 1. Differential cross sections taken from the IBANDL database.

\begin{tabular}{|l|l|l|l|}
\hline Reaction & $\begin{array}{l}\text { Angle } \\
(\mathrm{deg})\end{array}$ & $\begin{array}{l}\text { Energy } \\
\text { range }(\mathrm{MeV})\end{array}$ & Ref \\
\hline $\mathrm{D}\left({ }^{3} \mathrm{He},{ }^{4} \mathrm{He}\right) \mathrm{p}$ & 135 & $0.55-6$ & 50 \\
\hline${ }^{9} \mathrm{Be}\left({ }^{3} \mathrm{He}, \mathrm{p}_{0}\right){ }^{11} \mathrm{~B}$ & 150,90 & $1.8-5.1$ & 49 \\
\hline${ }^{9} \mathrm{Be}\left({ }^{3} \mathrm{He}, \mathrm{\alpha}_{0}\right){ }^{8} \mathrm{Be}$ & $150,125,90$ & $2.38-10.06$ & 51 \\
\hline${ }^{12} \mathrm{C}\left({ }^{3} \mathrm{He}, \mathrm{p}_{\mathrm{i}}\right){ }^{14} \mathrm{~N}(\mathrm{i}=0-4)$ & 90,150 & $1.6-5.01$ & 52 \\
\hline
\end{tabular}




\begin{tabular}{|l|l|l|l|}
\hline${ }^{12} \mathrm{C}\left({ }^{3} \mathrm{He}, \alpha_{0}\right){ }^{11} \mathrm{C}$ & 159.4 & $1.85-5.35$ & 53 \\
\hline${ }^{13} \mathrm{C}\left({ }^{3} \mathrm{He}, \mathrm{p}_{\mathrm{o}}\right)^{15} \mathrm{~N}$ & 150,120 & $1.89-3.8$ & 54 \\
\hline${ }^{14} \mathrm{~N}\left({ }^{3} \mathrm{He}, \mathrm{p}_{\mathrm{i}}\right)^{16} \mathrm{O}(\mathrm{i}=0-7)$ & $150,135,90$ & $2-5.5$ & $55-57$ \\
\hline${ }^{14} \mathrm{~N}\left({ }^{3} \mathrm{He}, \alpha_{0}\right){ }^{16} \mathrm{O}$ & 135,90 & $1.58-2.78$ & 56 \\
\hline
\end{tabular}

The saved list files were used for off-line analysis to create PIXE and NRA spectra from selected regions within the measured

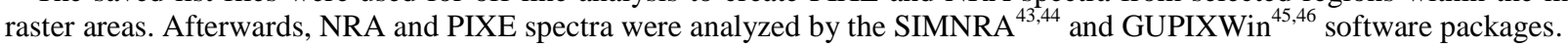

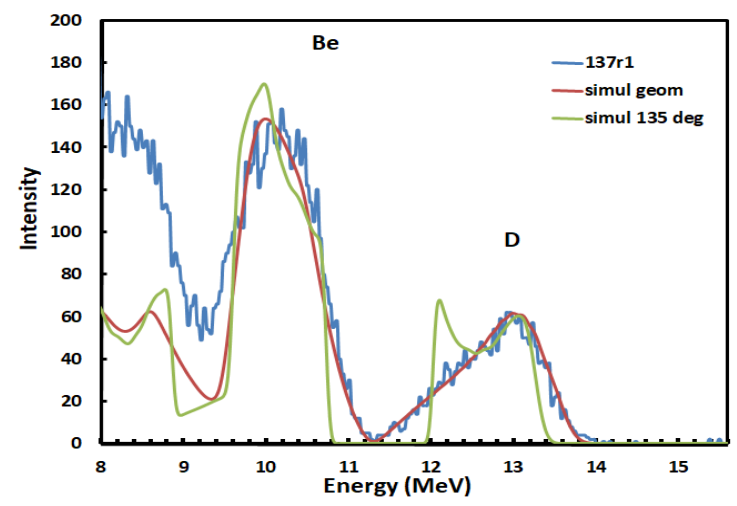

Figure 3. Influence of geometrical effects on the analysis of the NRA spectra from the sample with deuterium present. The blue line is the measured spectrum. The SIMNRA simulation for $135 \mathrm{deg}$ is shown as the green line. The simulated spectrum corrected for the geometrical effect is shown as the red line.

To obtain elemental concentrations, PIXE and NRA data were handled sequentially (iteratively) in a similar way as reported by de Viguerie et al. ${ }^{47}$ in their study of paint layers using simultaneous PIXE and EBS. Although more advanced techniques are available $^{17,25}$, this method provides reliable results on elemental concentrations when a higher accuracy is not required and in relatively simple cases when samples can be modeled as homogeneous. We started the iterative process by fitting the NRA spectrum and assuming only the presence of $\mathrm{Be}$ and $\mathrm{D}$. The product of the number of ${ }^{3} \mathrm{He}$ ions collected during the measurement and the detector solid angle was determined in such a way to assess the charge input needed to calculate the first iterative concentrations of heavier elements present in the PIXE spectra (with Be and D as invisible elements in the iterative matrix procedure). The result was then used as another input for NRA analysis, and after several iterations, consistent results could be obtained.

The measured NRA spectra were simulated with the SIMNRA using differential cross sections taken from the IBANDL database $^{48}$ and are listed in Table 1. Fig. 2 shows the measured NRA spectrum from the $25-\mu \mathrm{m}$-thick Be foil as a function of the detected energy. Although only the highest energy region was used in the analysis, the figure shows simulated contributions from the ${ }^{9} \mathrm{Be}\left({ }^{3} \mathrm{He}, \mathrm{p}_{\mathrm{i}}\right)^{11} \mathrm{~B}$ (i=1 to 7) reactions available at IBANDL. A significant portion of the misfit is due to neglecting multiple channels that are open that cannot presently be simulated due to the unavailability of reliable data.
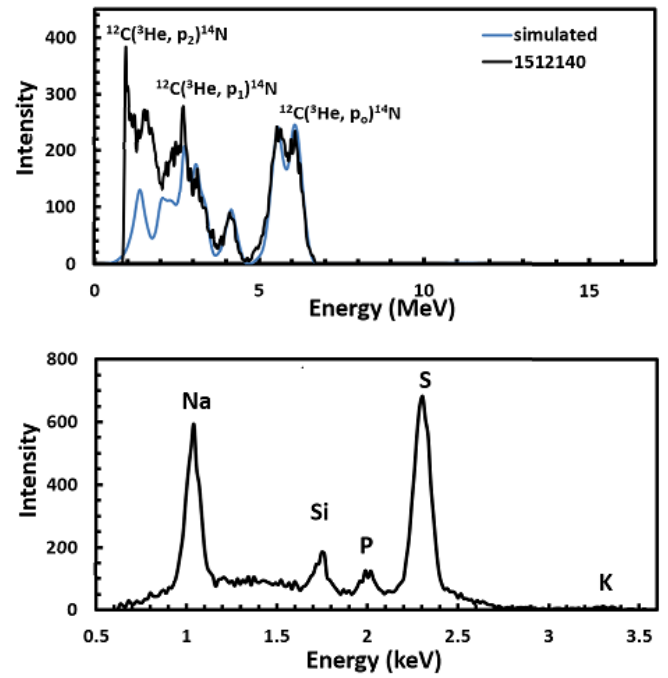

Figure 4. a) Measured NRA spectrum of the carbon sticky pad. The high energy part of the spectrum was well simulated with the use of the cross sections available from the IBANDL database and could be used in the analysis. The low energy portion did not fit well due to multiple channels that could not be simulated. b) The measured PIXE spectrum of the sticky pad. The presence of $\mathrm{S}$ and Na is clearly observable with some traces of $\mathrm{Si}, \mathrm{P}$ and $\mathrm{K}$. 
In the simulation of the NRA spectra, we had to take into account the effect of the large PDSSB detector aperture and the solid angle with the resulting spread of exit and reaction angles. Therefore, the NRA spectra simulations with SIMNRA were performed for scattering angles between 116 and $154 \mathrm{deg}$. The final simulated spectra were obtained by the summation of the simulated spectra with respective weighting factors to account for geometrical effects due to this large detector solid angle. Altogether, the summation was performed using 19 segments, and in the calculation, spherical trigonometric formulae were used. During the calculation of these geometrical corrections, we found that the additional path length correction due to the foil (in front of the NRA detector) thickness variation with the scattering angle was minimal. Fig. 3 illustrates the importance of the geometrical correction for the analysis of NRA spectra from samples with an evident D presence. The simulated spectrum with a geometrical correction (red line) follows the shapes of the highest Be peak and D feature in the measured spectrum very well, assuming homogeneous distribution of D with depth.

Fig. 4 shows the NRA and PIXE spectra of the carbon pad tape. The NRA shows the measured carbon spectrum from the pad together with the simulated NRA spectrum obtained by SIMNRA with a geometrical correction due to the large solid angle. The high energy part of the spectrum was simulated well with the use of cross sections available from the IBANDL database. The low energy portion did not fit well due to multiple channels which could not be simulated, not to mention the neutron production threshold $(1.44 \mathrm{MeV})$, which is easily exceeded. The simultaneously collected PIXE spectrum shows clear presence of $\mathrm{Na}$ and $\mathrm{S}$ at both concentrations below $1 \mathrm{w} \%(0.9 \mathrm{w} \% \mathrm{Na}$ and $0.8 \mathrm{w} \% \mathrm{~S})$ with traces of $\mathrm{Si}, \mathrm{P}, \mathrm{K}$ and $\mathrm{Ca}$.

The PIXE spectra were not affected by occasional hits of energetic ions onto the detector crystal due to the relatively small frequency of such events. Since all backscattered ${ }^{3} \mathrm{He}$ ions stopped in the detector Be foil, only high energy nuclear reactions products can hit the detector volume. The distance of the PIXE detector from the target was optimized to reduce the frequency of such events to minimize the possible influence on the measured PIXE spectra. Here it is important to note that the NRA detector solid angle is about 26 times larger then the PIXE detector solid angle.

Figures 2 and 4 clearly show that the highest energy peak in the carbon NRA spectrum overlaps with the peak structure of the Be NRA spectrum at about $6 \mathrm{MeV}$. The simulation shows that the Be NRA signal occurs from the surface up to a depth of $1.8 \times 10^{20}$ $\mathrm{at} / \mathrm{cm}^{2}$, which corresponds to a $15 \mu \mathrm{m}$ Be thickness (using a Be mass density of $1.803 \mathrm{~g} / \mathrm{cm}^{3}$ ).

\section{RESULTS AND DISCUSSION}

Visual examination of the pad clearly shows that the majority of collected particles are located close to its left edge (Fig. 1). At first, we made a fast screening and focused on the region rich in particles. The screening showed that this region consists mainly from the same type of particles, i.e., Be-rich particles with some D and $\mathrm{Cr}, \mathrm{Fe}, \mathrm{Ni}$ and $\mathrm{W}$, as shown by their peaks in the PIXE spectra. Then, we performed 2D scans with higher statistics within the marked area shown in the insert of Fig. 1(b), starting from the left side that is rich in particles.

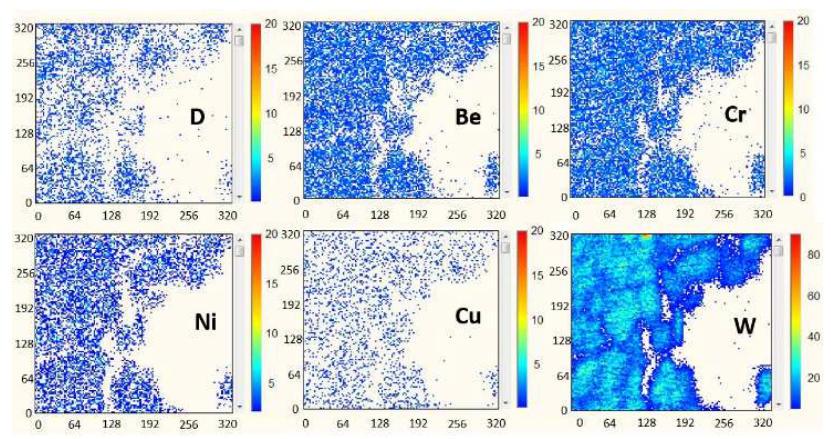

Figure 5. 2D distribution maps of the major elements from the selected scanned area in the region rich with particles that had the largest detected deuterium peaks. The scan size is $320 \times 320 \mu \mathrm{m}^{2}$, and the resolution is $128 \times 128$ pixels.

Fig. 5 shows the 2D distribution maps of the major elements (i.e., their intensity maps) from one of the selected scanned areas in the region with a high particle density, which shows the highest $\mathrm{D}$ peak intensities compared to Be. The white areas on the map are pixels without events or with number of counts below the estimated background. Fig. 6 shows the related PIXE and NRA spectra used to create the 2D maps. Many dust particles of different sizes varying between several $\mu \mathrm{m}$ to about $60 \mu \mathrm{m}$ is clearly seen. Be and D 2D maps were extracted from the NRA spectrum, which clearly shows the presence of $\mathrm{C}$. The vast majority of $\mathrm{C}$ signal originated from the sticky pad, as well as $\mathrm{Na}, \mathrm{S}, \mathrm{Si}$ and $\mathrm{K}$ peaks in the corresponding PIXE spectrum, which also shows that $\mathrm{Cr}$, Ni, Fe and $\mathrm{W}$ are major elements in addition to some $\mathrm{Cu}$ and $\mathrm{Ti}$. 

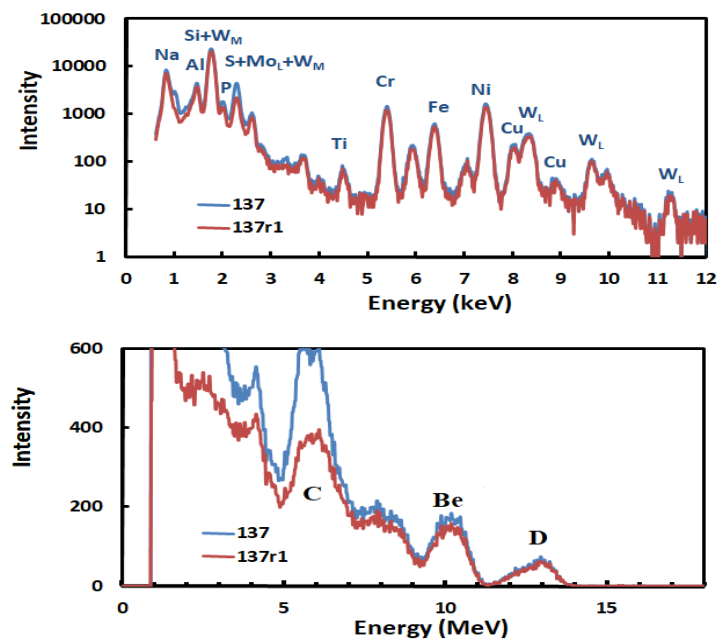

Figure 6. Respective PIXE and NRA spectra from the scanned area from Figure 5.

Off line analysis was performed by selecting the region of interest (ROI) corresponding to the pixels with the presence of W in the related 2D map (Fig. 5). The related PIXE and NRA spectra are shown at Fig. 6 in red. Be and D from NRA are correlated with $\mathrm{W}, \mathrm{Cr}, \mathrm{Ni}$ and $\mathrm{Cu}$ from PIXE, and all these elements are correlated with dust particles. The peak at around $6 \mathrm{MeV}$ corresponding to $\mathrm{C}$ is considerably reduced within the selected ROI.

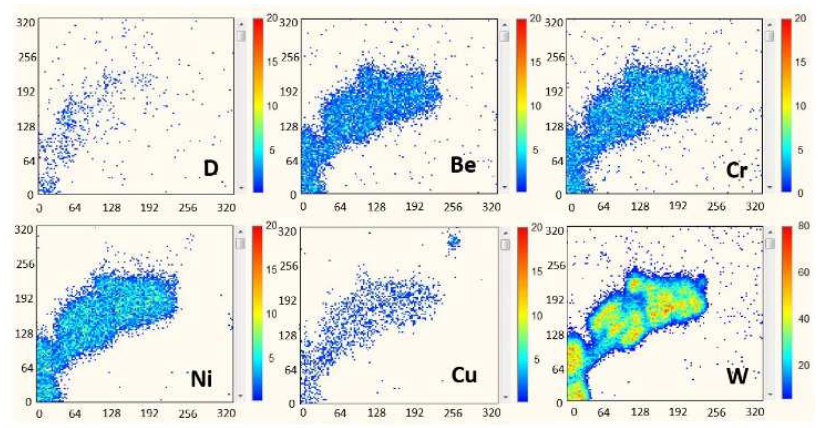

Figure 7. 2D distribution maps of the major elements from the selected scanned area at the right edge of the region that is rich in particles. The scan size is $320 \times 320 \mu \mathrm{m}^{2}$, and the resolution is $128 \times 128$ pixels.

Fig. 7 shows dust particles located at the edge of the large conglomerate of particles on the left (Fig. 1). Associated spectra from the scanned area and from the region corresponding to the presence of $\mathrm{W}$ in the PIXE 2D map are shown in Fig. 8. The elemental composition of dust particles is very similar to the one in Fig. 5, except that $\mathrm{D}$ shows a non-even areal distribution. Therefore, the total $\mathrm{D}$ content in the region covered by dust particles is lower than in the previous case, as is clearly observable from the NRA spectrum (red line) in Fig. 8. 

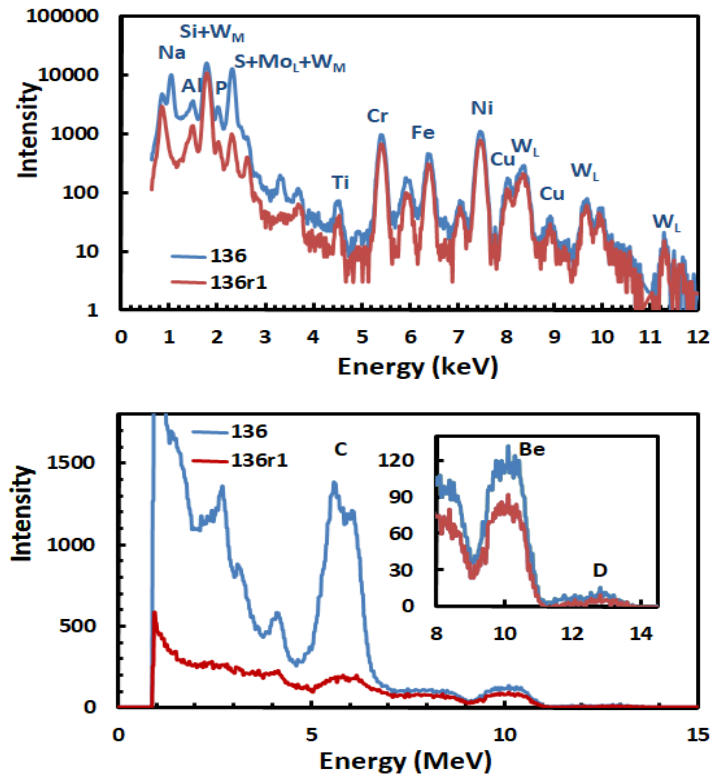

Figure 8. Respective PIXE and NRA spectra from the scanned area from Figure 6.

By moving along the marked area in Fig. 1 towards the center of the sticky pad, the density of dust particles considerably drops. A number of small particles that were several $\mu \mathrm{m}$ in size, some of which were observed in the region on the left, increased somewhat. Small particles containing Al and/or Si were observed, which in some cases were accompanied by some other elements, such as $\mathrm{Fe}, \mathrm{Cu}$ or Ti. Small Al particles could originate from structural materials of the robotic arm for in-vessel operations, while those containing $\mathrm{Al}$ and $\mathrm{Si}$ can be related to ceramics from diagnostic or heating systems in $\mathrm{JET}^{1,2,10}$. One particle containing W and Mo in a concentration ratio of about 2:1 was identified. These can be associated with coatings on the PFCs.

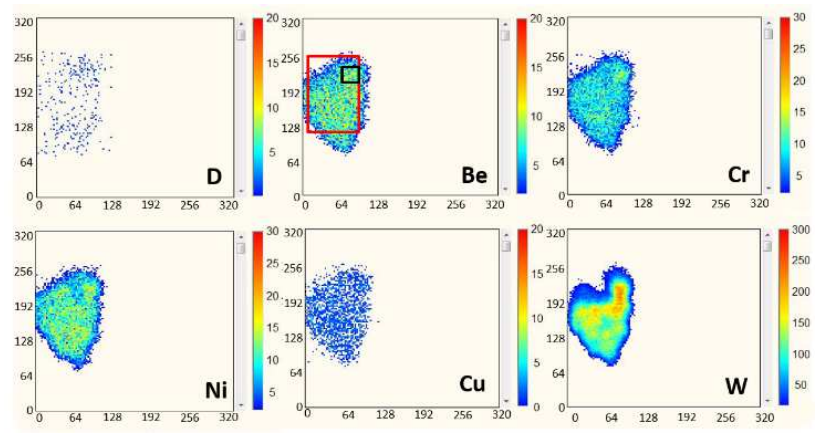

Figure 9. 2D distribution maps of the major elements from the selected scanned area showing one isolated particle with a size of about 100 $\mu \mathrm{m}$. The scan size is $320 \times 320 \mu \mathrm{m}^{2}$ and the resolution is $128 \times 128$ pixels.

Among such small particles, we also observed a few larger particles or conglomerates of particles rich in Be. An example of one such particle is shown at Fig. 9. As shown in the PIXE and NRA spectra, its constitution is very similar to the ones already discussed. The particle contains mainly Be with some presence of $\mathrm{W}, \mathrm{Ni}, \mathrm{Cr}, \mathrm{Fe}, \mathrm{Cu}, \mathrm{Ti}$ and unevenly distributed $\mathrm{D}$. Fig. 10 shows two sets of PIXE/NRA spectra related to the two selected areas marked in the 2D Be map in Fig. 9 as red and black rectangles. At the higher energy region above the D peak, the NRA shows traces of nitrogen. 

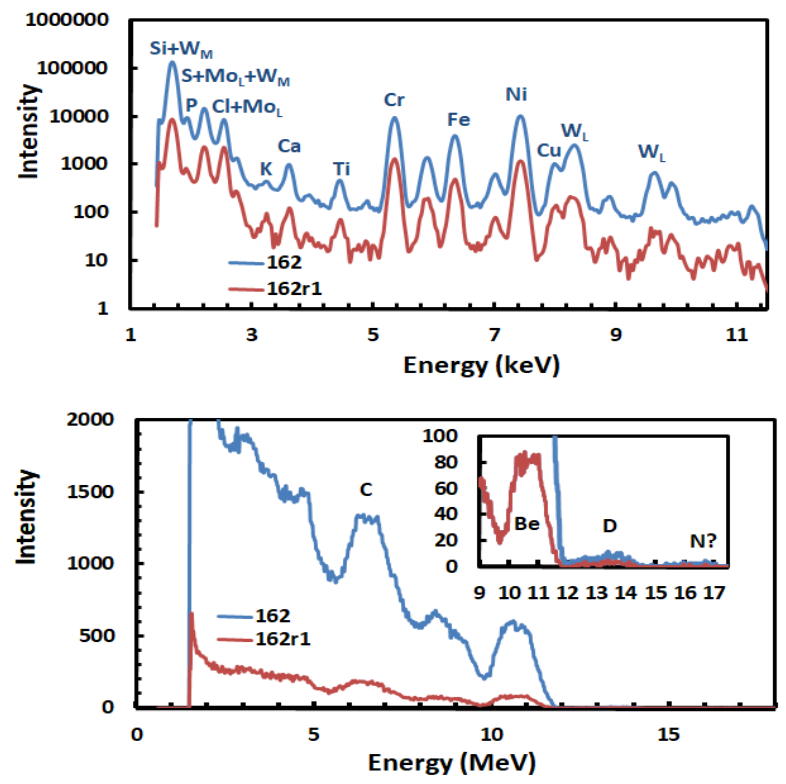

Figure 10. Respective PIXE and NRA spectra from the scanned area from Figure 9.

Table 2. Average elemental concentrations in at \% related to the areas from Figures 5, 7, 9 and their estimated uncertainties.

\begin{tabular}{|l|l|l|l|l|l|l|l|l|}
\hline & $\mathrm{D}$ & $\mathrm{Be}$ & $\mathrm{Ti}$ & $\mathrm{Cr}$ & $\mathrm{Fe}$ & $\mathrm{Ni}$ & $\mathrm{Cu}$ & $\mathrm{W}$ \\
\hline Figure 5 & 3.3 & 91 & 0.02 & 0.8 & 0.6 & 2.9 & 0.5 & 0.9 \\
\hline & $10 \%$ & $10 \%$ & $14 \%$ & $8 \%$ & $8 \%$ & $8 \%$ & $9 \%$ & $9 \%$ \\
\hline Figure 7 & 0.5 & 96.7 & 0.01 & 0.4 & 0.3 & 1.2 & 0.2 & 0.5 \\
\hline & $13 \%$ & $10 \%$ & $14 \%$ & $8 \%$ & $8 \%$ & $8 \%$ & $9 \%$ & $9 \%$ \\
\hline Figure 9 & 0.5 & 97.1 & 0.01 & 0.5 & 0.3 & 1.3 & 0.2 & 0.24 \\
\hline & $13 \%$ & $10 \%$ & $14 \%$ & $8 \%$ & $8 \%$ & $8 \%$ & $9 \%$ & $9 \%$ \\
\hline
\end{tabular}

Table 2 shows the elemental concentrations obtained from the iterative analysis of the NRA and PIXE spectra related to the areas shown in Figs. 5, 7 and 9, together with their relative uncertainties. Statistical and fit uncertainties of the spectra have contributions of 6 to $10 \%$ for $\mathrm{D}, 6 \%$ for $\mathrm{Be}, 5 \%$ for $\mathrm{Cr}, \mathrm{Fe}, \mathrm{Ni}, 7 \%$ for $\mathrm{Cu}$ and $\mathrm{W}$, and $12 \%$ for Ti. The uncertainties of the NRA cross sections used in the analysis are $3.5 \%$ for $\mathrm{D}$ and $\approx 3 \%$ for the $\mathrm{Be} \mathrm{p}_{\mathrm{o}} / \alpha_{\mathrm{o}}$ channels, and we have to add $5 \%$ uncertainty related to their angular dependence between 116 and $154 \mathrm{deg}$. The uncertainties of the solid angle ratios is $5.3 \%$, and for the PIXE cross sections, it is estimated to be $3 \%$. All these contributions were taken together and are provided in Table 2. However, we also have to keep in mind that in the analysis we assumed that our dust particles are flat, thick and homogeneous, which is certainly only an approximation, as shown in the SEM analysis and in previous reports ${ }^{6,10,11}$; however, this was justified with our Be and D peak shapes in the NRA simulations. In the cited reports, particles with rough irregular surfaces, fractures, voids and nanometer-sized W inclusions inside the material were observed.

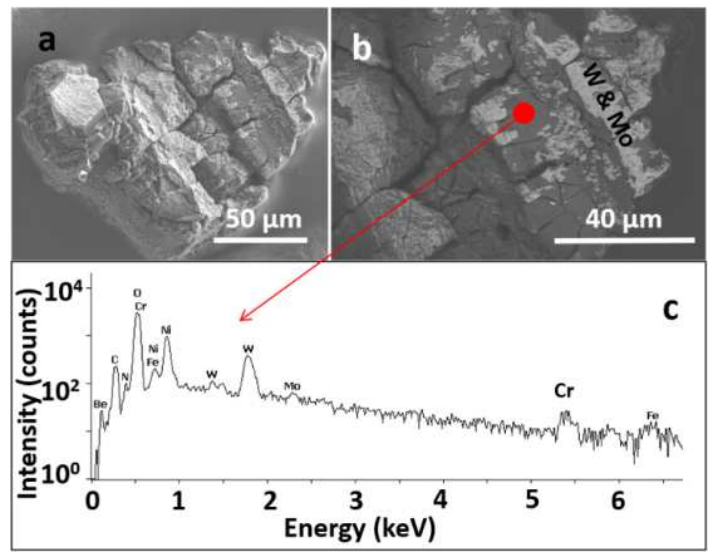

Figure 11. Microscopy image and X-ray spectrum of a dust particle: (a) secondary electron and (b) back-scattered electron images; (c) Xray spectrum recorded in the position marked with a dot in image (b). 
Fig. 11 shows complementary information obtained from this particle surface by SEM analysis. Figs 11.(a) and (b) show secondary and back-scattered electron images of this dust particle, respectively. The back-scattered electron image indicates the surface areas of the different atomic numbers ( $\mathrm{Z}$ contrast). Darker parts are rich in low- $\mathrm{Z}$ elements, especially Be, whereas the main constituents of brighter areas are tungsten and molybdenum. The latter were most likely detached from the W-Mo coatings on the carbon fiber composite tiles. This object is typical for the deposition zone on Tile 0 , where layers reach a thickness of $20-40 \mu \mathrm{m}$. The particle is fairly large $(100 \times 120 \mu \mathrm{m})$; however, there is quite a fractured structure, suggesting that the co-deposit may disintegrate into much smaller pieces.

The SEM-EDS X-ray spectrum in Fig. 11 (c) shows the existence of a mix of low-Z and high-Z elements: Be, C, N, Ni, Cr, Fe, Mo and W. The presence of these elements as detected by SEM-EDX from the sample surface (up to a depth of $1 \mu \mathrm{m}$ ) is in agreement with the PIXE, which, however, shows several additional elements and gives information from the surface and below to a depth of about $15 \mu \mathrm{m}$.

Regarding the analysis of $\mathrm{C}$, we assume that its main origin is from the carbon sticky pad. This is supported by the comparisons of the NRA spectra from Figures 6, 8 and 10. It is possible that some small amount of carbon is associated with the particles. Precise analysis of this kind of sample would require precise modeling of the Be NRA spectra in the energy region of the main C peak at approximately $6 \mathrm{MeV}$, which would require good knowledge of Be related cross sections in that energy region.

Table 2 shows that low $\mathrm{D} / \mathrm{Be}$ concentration ratios from about 0.5 to $3.6 \%$ have been determined. A loss of D due to ion bombardment has been reported in prior studies ${ }^{50}$. Loss of D in D-implanted Be thin films was studied by Nagata et al. ${ }^{59}$, who reported that for a He ion fluency of $3 \times 10^{17}$ ions $/ \mathrm{cm}^{2}$ (similar to the present values), approximately $75 \%$ of D is retained in a thin Be film. Scherzer et al. ${ }^{60}$ reported that the amount of retained $\mathrm{D}$ in thick $\mathrm{BeO}$ is higher than in thin nm films.

The SEM-EDX spectrum in Fig. 11(c) also indicates the possibility that oxygen is present in the sample. However, the sample also contains Cr. Since K X-rays of O are overlapped with the L X-ray lines of Cr, characterization of O is not possible. The $\mathrm{O}$ in the samples could originate from plasma impurities and exposure to air during sampling and storage ${ }^{10,58}$. Our ${ }^{3} \mathrm{He}$ NRA measurements are also blind to O. Regardless, we determined that Be NRA yields from our samples containing Be are within 10\% compared with the Be foil yields. This confirms that if $\mathrm{O}$ is present in our samples, its content is below $10 \%$. At such low levels, even He RBS cannot provide precise $\mathrm{O}$ concentrations due to the presence of heavier metals in the samples.

Fig. 11(c) shows small Mo L peak at about $2.3 \mathrm{keV}$. Fig. 12 shows the related PIXE spectrum in which the peak at the same position is observed, and it is marked as $\mathrm{S}+\mathrm{MoL}+\mathrm{WM}$ since it can overlap with $\mathrm{S} \mathrm{K \alpha}$, Mo-L $\alpha$ and with a small contribution from the W-M X-ray lines. Fig. 4 shows that the sticky pad contains S, and therefore, we performed quantitative analysis in GUPIXWin without Mo (i.e., assuming that the main contribution to this line is from parasitic $\mathrm{S}$ from the sticky pad with some contribution from the W M line). The inclusion of the Mo-L line in the GUPIXWin analysis results shows possible concentration of Mo in the sample of about $0.8 \mathrm{w} \%$ or below. The PIXE spectra shown in Figures 5 and 8 are similar, and inclusion of the Mo-L contribution in the analysis results shows possible Mo concentrations of up to $2.9 \mathrm{w} \%$ and $1.1 \mathrm{w} \%$, respectively.

\section{CONCLUSIONS}

Simultaneous use of NRA and PIXE spectroscopies with 2D scanning of focused ${ }^{3} \mathrm{He}$ ion beams over areas of up to $1 \times 1 \mathrm{~mm}^{2}$ can be used for quantitative determination of elemental concentrations of dust particles from tokamaks with metal-like walls. Almost all major and minor elements can be detected, including deuterium. Due to low ${ }^{3} \mathrm{He}$ ion currents, it is necessary to use largearea NRA detectors with a large solid angle, which requires spectral integration over all the angles to obtain proper simulation of the NRA spectra. Quantitative analysis can be obtained by an iterative PIXE-NRA calculation procedure using GUPIXWin and SIMNRA analytical tools after calibration of the experimental setup with appropriate standards.

The method developed has been used for the analysis of dust particles sampled using a sticky carbon pad from the inner divertor tile after the second ILW campaign (2013-2014), which involved $19.5 \mathrm{~h}$ of plasma operation (13.5 h of X-point plasma) with a total energy input of $201 \mathrm{GJ}$.

Two types of dust particles have been found:

1) NRA shows Be with some $\mathrm{D}$. This is in addition to $\mathrm{Cr}, \mathrm{Fe}, \mathrm{Ni}, \mathrm{Cu}$, and $\mathrm{W}$, as observed by PIXE. Particles are present in thick 'layers', i.e., with Be not only on the surface but spread to at least 10 to $15 \mu \mathrm{m}$ deep. Be concentrations are high, i.e., larger than 90 at $\%$. The D concentration is up to about 3.2 at\% or lower. Among heavier elements, $\mathrm{W}$ and Ni are major elements, which are accompanied by $\mathrm{Cr}$ and $\mathrm{Fe}$ together with traces of $\mathrm{Ti}$ and $\mathrm{Cu}$. These are particles from the JET ILW D-T operation, having mixed columnar and stratified structure and are detached from the deposition zone, shaped as thick Be-based layers, with presence of $\mathrm{D}$, i.e., fusion fuel; and including $\mathrm{W}, \mathrm{Ni}, \mathrm{Cr}, \mathrm{Fe}$, Ti and $\mathrm{Cu}$, showing origin of these particles are Be-covered tiles. The results show a non-uniform distribution of species in loosely bound deposits/dust particulates.

2) Smaller particles for which NRA shows only C (background carbon sticky tape pad) in addition to Na, Si S, P, K (background carbon sticky tape pad) and rich in $\mathrm{Al}$ and/or $\mathrm{Si}$, in some cases accompanied by other elements, such as $\mathrm{Fe}, \mathrm{Cu}$ or $\mathrm{Ti}$, with the exception of one quite different particle that contains $\mathrm{W}$ and Mo in a concentration ratio of about 2:1.

As stated in the Introduction, detailed studies on dust have been conducted at JET in response to ITER needs for safety assessment. Important outcomes of this particular work include: (i) the first quantitative results of elemental concentrations of dust particle types of importance for ITER and (ii) in case of Be-containing particles, we confirmed quantitatively high Be concentrations (over 90 at\%) with low D/Be concentration ratios (below 3.6\%) and areal distribution of D and metals in loose matter collected using carbon sticky pads. This work will be continued on dust specimens collected from other locations and using different sampling methods. 


\section{AUTHOR INFORMATION}

\section{Corresponding author}

*E-mail: stjepko.fazinic@irb.hr. Phone: +385 993174866

\section{Notes:}

The authors declare no competing financial interest.

\section{ACKNOWLEDGMENT}

This work has been carried out within the framework of the EUROfusion Consortium and has received funding from the Euroatom research and training programme 2014-2018 under grant agreement No 633053. The views and opinions expressed herein do not necessarily reflect those of the European Commission.

\section{REFERENCES}

(1) Matthews, G. F.; Edwards, P.; Hirai, T.; Kear, M.; Lioure, A.; Lomas, P.; Loving, A.; Lungu, C.; Maier, H.; Mertens, P.; Neilson, D.; Neu, R.; Pamela, J.; Philipps, V.; Piazza, G.; Riccardo, V.; Rubel, M.; Ruset, C.; Villedieu, E.; Way, M.; the ITER-like Wall Project Team. Phys. Scr. 2007, 2007, 137-143.

(2) Matthews, G. F.; Beurskens, M.; Brezinsek, S.; Groth, M.; Joffrin, E.; Loving, A.; Kear, M.; Mayoral, M. L.; Neu, R.; Prior, P.; Riccardo, V.; Rimini, F.; Rubel, M.; Sips, G.; Villedieu, E.; de Vries, P.; Watkins, M. L.; EFDA-JET contributors. Phys. Scr. 2011, 2011, 014001014001 .

(3) Braams, B. J. Characterisation of Size, Composition and Origins of Dust in Fusion Devices, IAEA, 2013, https://wwwnds.iaea.org/publications/indc/indc-nds-0607.pdf

(4) Merola, M.; Escourbiac, F.; Raffray, R.; Chappuis, P.; Hirai, T.; Martin, A. Fusion Eng. Des. 2014, 89, 890-895.

(5) Widdowson, A.; Alves, E.; Ayres, C. F.; Baron-Wiechec, A.; Brezinsek, S.; Catarino, N.; Coad, J. P.; Heinola, K.; Likonen, J.; Matthews, G. F.; Mayer, M.; Rubel, M.; JET-EFDA Contributors. Phys. Scr. 2014, 2014, 014010-014010.

(6) Fortuna-Zaleśna, E.; Grzonka, J.;Rubel, M.; Garcia - Carrasco, A.; Widdowson, A.; Baron - Wiechec, A.; Ciupiński, L.; JET Contributors. Nucl. Mater. Energy 2017, 12, 582-587.

(7) Coad, J. P.; Alves, E.; Barradas, N. P.; Baron - Wiechec, A.; Catarino, N.; Heinola, K.; Likonen, J.; Mayer, M.; Matthews, G. F.; Petersson, P.; Widdowson, A.; JET-EFDA Contributors. Phys. Scr. 2014, 2014, 014012-014012.

(8) Lagoyannis, A.; Tsavalas, P.; Mergia, K.; Provatas, G.; Triantou, K.; Tsompopoulou, E.; Rubel, M.; Petersson, P.; Widdowson, A.; Harissopulos, S.; Mertzimekis, T. J.; the JET contributors. Nucl. Fusion 2017, 57, 076027-076027.

(9) Baron - Wiechec, A.; Widdowson, A.; Alves, E.; Ayres, C. F.; Barradas, N. P.; Brezinsek, S.; Coad, J. P.; Catarino, N.; Heinola, K.; Likonen, J.; Matthews, G. F.; Mayer, M.; Petersson, P.; Rubel, M.; van Renterghem, W.; Uytdenhouwen, I.; JET-EFDA contributors. J. Nucl. Mater. 2015, 463, 157-161.

(10) Baron-Wiechec, A.; Fortuna-Zaleśna, E.; Grzonka, J.; Rubel, M.; Widdowson, A.; Ayres, C.; Coad, J. P.; Hardie, C.; Heinola, K.; Matthews, G. F.; JET Contributors. Nucl. Fusion 2015, 55, 113033-113033.

(11) Fortuna-Zaleśna, E.; Grzonka, J.; Moon, S.; Rubel, M.; Petersson, P.; Widdowson, A.; JET Contributors. Phys. Scr. 2017, 2017, 014038014038.

(12) Balden, M.; Endstrasser, N.; Humrickhouse, P. W.; Rohde, V.; Rasinski, M.; von Toussaint, U.; Elgeti, S.; Neu, R.; the ASDEX Upgrade Team. Nucl. Fusion 2014, 54, 073010-073010.

(13) Nicolaides, C. A.; Komninos, Y.; Beck. D. R. Phys. Rev. A 1983, 27, $3044-3052$.

(14) Dick, C. E.; Lucas, A. C. Phys. Rev. A 1970, 2, 580-586.

(15) Feser, K. Phys. Rev. Lett. 1972, 28, 1013-1015.

(16) Breese, M. B. H. in Handbook of Modern Ion Beam materials Analysis, 2nd Edition.; Wang, Y.; Nastasi, M., Eds.; Materials Research Society: Warrendale, 2009; pp 285-303.

(17) Jeynes, C.; Colaux, J. L. Analyst 2016, 141, 5944-5985

(18) Rubel, M. Phys. Scr. 2006, T123, 54-65.

(19) Rubel, M.; Coad, J. P; Likonen, J.; Philipps, V. Nucl. Instrum. Methods Phys. Res., Sect. B 2009, $267,711-717$.

(20) Jeynes, C.; Barradas, N. P.; Szilagyi, E.; Anal. Chem. 2012, 84, 6061-6069.

(21) Romano, F. P.; Caliri, C.; Cosentino, L.; Gammino, S.; Mascali, D.; Pappalardo, L.; Rizzo, F.; Scharf, O. U. H. P.; Santos, H. C. Anal. Chem. 2016, 88, 9873-9880.

(22) Hunault, M. O. J. Y.; Loisel, C.; Bauchau, F.; Lemasson, Q.; Pacheco, C.; Pichon, L.; Moignard, B.; Boulanger, K.; Hérold, M.; Calas, G.; Pallot-Frossard, I. Anal. Chem. 2017, 89, 6277-6284.

(23) Huszank, R.; Csedreki, L.; Torok, Z. Anal. Chem. 2017, 89, 1558-1564.

(24) Bailey, M. J.; Morgan, R. M.; Comini, P.; Calusi, S.; Bull, A. Anal. Chem. 2012, 84, 2260-2267.

(25) Barradas, N. P.; Mateus, R.; Fonseca, M.; Reis, M. A.; Lorenz, K.; Vickridge, I. Nucl. Instrum. Methods Phys. Res., Sect. B 2010, 268, 18291832 .

(26) Kelemen, M.; Založnik, A.; Vavpetič, P.; Pelicon, P.; Kakola, A.; Meisi, G.; Oberkofler, M.; Krieger, K.; Brezinsek, S.; Markelj, S.; the ASDEX Upgrade Team; EUROfusion MST1 Team, Phys. Scr. 2017, 2017, 014067-014067.

(27) Bykov, I.; Bergsaker, H.; Petersson, P.; Likonen, J.; Possnert, G.; Widdowson, A. Nucl. Instrum. Methods Phys. Res., Sect. B 2015, 342, 1928.

(28) Alves, L. C.; Alves, E.; Barradas, N. P.; Mateus, R.; Carvalho, P.; Coad, J. P.; Widdowson, A. M.; Likonen, J.; Koivuranta, S. Nucl. Instrum. Methods Phys. Res., Sect. B 2010, 268, 1991-1996.

(29) Petersson, P.; Kreter, A.; Possnert, G.; Rubel, M. Nucl. Instrum. Methods Phys. Res., Sect. B 2010, $268,1833-1837$.

(30) Petersson, P.; Possnert, G.; Rubel, M.; Dittmar, T.; Pégourié, B.; Tsitrone, E.; Wessel, E. J. Nucl. Mater. 2011, 415, S761-S764.

(31) Petersson, P.; Rubel, M.; Possnert, G.; Pégourié, B. Phys. Scr. 2011, 2011, 014014-014014.

(32) Petersson, P.; Rubel, M.; Possnert, G.; Brezinsek, S.; Pegouried, B. Nucl. Instrum. Methods Phys. Res., Sect. B 2012, $273,113-117$.

(33) Bergsåker, H.; Petersson, P.; Bykov, I.; Possnert, G.; Likonen, J.; Koivuranta, S.; Coad, J. P.; Widdowson, A. M.; JET EFDA contributors. J. Nucl. Mater. 2013, 438, S668-S672.

(34) Bykov, I.; Bergsåker, H.; Petersson, P.; Likonen, J.; Possnert, G. Nucl. Instrum. Methods Phys. Res., Sect. B 2014, 332, $280-285$. 
(35) Rubel, M.; Petersson, P.; Zhou, Y.; Coad, J. P.; Lungu, C.; Jepu, I.; Porosnicu, C.; Matveev, D.; Kirschner, A.; Brezinsek, S.; Widdowson, A.; Alves, E.; JET Contributors. Nucl. Fusion 2017, 57, 066027-066027.

(36) Mayer, M.; Gauthier, E.; Sugiyama, K.; von Toussaint, U. Nucl. Instrum. Methods Phys. Res., Sect. B 2009, 267, 506-512.

(37) Rubel, M.; Coad, J. P.; Likonen, J.; Philipps, V.; JET-EFDA Contributors. Nucl. Instrum. Methods Phys. Res., Sect. B 2009, $267,711-717$.

(38) A. Widdowson, A. Baron-Wiechec, J.P. Coad, K. Heinola, J. Likonen, C. Lungu, G.F. Matthews, M. Rubel, Phys. Scr. T167 (2016) 014057

(39) Jakšić, M.; Bogdanović Radović, I.; Bogovac, M.; Desnica, V.; Fazinić, S.; Karlušić, M.; Medunić, Z.; Muto, H.; Pastuović, Ž.; Siketić, Z.; Skukan, N.; Tadić, T. Nucl. Instrum. Methods Phys. Res., Sect. B 2007, 260, 114-118.

(40) Maenhaut, W.; Raemdonck, H. Nucl. Instrum. Methods Phys. Res., Sect. B 1984, 1, 123-136.

(41) Fazinić, S.; Mandić, L.; Tadić, T.; Božičević, I. Nucl. Instrum. Methods Phys. Res., Sect. B 2013, $297,94-101$.

(42) Bogovac, M.; Bogdanović, I.; Fazinić, S.; Jakšić, M.; Kukec, L.; Wilhelm, W. Nucl. Instrum. Methods Phys. Res., Sect. B 1994, B89, 219222.

(43) Mayer, M. SIMNRA User's Guide, Report IPP 9/113, Max-Planck-Institut für Plasmaphysik, Garching, Germany, 1997.

(44) Rauhala, E.; Barradas, N. P.; Fazinić, S.; Mayer, M.; Szilágyi, E.; Thompson, M. Nucl. Instrum. Methods Phys. Res., Sect. B 2006, 244, 436456.

(45) Campbell, J. L.; Boyd, N. I.; Grassi, N.; Bonnick, P.; Maxwell, J. A. Nucl. Instrum. Methods Phys. Res., Sect. B 2010, $268,3356-3363$.

(46) Blaauw, M.; Campbell, J. L.; Fazinić, S.; Jakšić, M.; Orlic, I.; Van Espen, P. Nucl. Instrum. Methods Phys. Res., Sect. B 2002, B189, 113122.

(47) de Viguerie, L.; Beck, L.; Salomon, J.; Pichon, L.; Walter, Ph. Anal. Chem. 2009, 81, 7960-7966.

(48) https://www-nds.iaea.org/exfor/ibandl.htm

(49) Wolicki, E. A.; Holmgren, H. D.; Johnston, R. L.; Geer Illsley, E. Phys. Rev. 1959, 116, 1585.

(50) Alimov, V. Kh.; Mayer, M.; Roth, J. Nucl. Instrum. Methods Phys. Res., Sect. B, 2005, 234, 169-175.

(51) Bilwes, B.; Bilwes, R.; Ferrero, J. L.; Garcia, A. J. Phys. (Paris). 1978, 39, 805-814.

(52) Johnston, R. L.; Holmgren, H. D.; Wolicki, E. A.; Geer Illsley, E. Phys. Rev. 1958, 109, 884-887.

(53) Kuan, H. M.; Bonner, T. W.; Risser, J. R. Nucl. Phys. 1964, 51, 481-517.

(54) Geer Illsley, A.; Holmgren, H. D.; Johnston, R. L.; Wolicki, E. A. Phys. Rev. 1957, 107, 538-539.

(55) McIntyre Jr., L. C.; Leavitt, J. A.; Ashbaugh, M. D.; Borgardt, J.; Andrade, E.; Rickards, J.; Oliver, A. Nucl. Instrum. Methods Phys. Res., Sect. $B$ 1996, 118, 219-223.

(56) Terwagne, G.; Cohen, D. D.; Collins, G. A. Nucl. Instrum. Methods Phys. Res., Sect. B 1994, 84, $415-420$.

(57) Gorodetzky, S.; Bassompierre, G.; St-Pierre, C.; Gallmann, A.; Wagner, P. Nucl. Phys. 1963, 43, 92-102.

(58) Rubel, M.; Waelbroeck, F.; Bergsåker, H.; Wienhold, P.; Emmoth, B. J. Nucl. Mater. 1989, 161,153 - 163.

(59) Nagata, S; Yamaguchi, S; Bergsåker, H.; Emmoth, B. Nucl. Instrum. Methods Phys. Res., Sect. B 1988, 33, 739-743

(60) Scherzer, BMU; Blewer, RS; Behrisch, R; Schulz, R; Roth, J; Borders, J; Langley, R. J. Nucl. Mater. 1979, 85\&86, 1025 - 1029. 